\title{
Auristela y Cenotia, personalidades horacianas en el Persiles
}

\author{
Clark COLAHAN
}

Salió en 1599 la primera traducción española de todo el corpus horaciano, en una edición bilingüe de Villén de Biedma que se editó en Granada. Consiguió un éxito de venta, todavía hoy quedando muchos ejemplares en bibliotecas españolas, y sería poco probable que Cervantes no la conociera. Aunque las fechas de la composición del Persiles hayan constituido un vivo tema de conversación erudita, un nutrido grupo de críticos se han expresado a favor de la hipótesis de que precisamente en 1599 empezara Cervantes a redactar la que sería su última novela. ${ }^{1}$ Claro que había traducciones italianas anteriores de todas las obras de $\mathrm{Horacio}^{2}$ pero la crítica, respaldada tanto por casos concretos como por el sentido común, ha llegado a la conclusión de que Cervantes prefería y solía leer los textos latinos e italianos en traducción castellana. ${ }^{3}$

1. La opinión de Carlos Romero, autor de la edición crítica, si bien discrepa, también fija la fecha por allí cerca, con una anterioridad de un año o dos. Sobre las fechas de composición del Persiles propuestas por la crítica, vea el detallado resumen de Romero en Miguel de Cervantes, 2004, Los trabajos de Persiles y Sigismunda, edición de Carlos Romero Muñoz, Madrid: Cátedra, 15-29.

2. La traducción del corpus entero que con más probabilidad conociera Cervantes se editó por primera vez en 1566: L'opere d'Oratio poeta lirico / comentate da Giouanni Fabrini da Fighine in lingua uulgare toscana ; con ordine, che 'l uulgare e comento del latino: et il latino e comento del uulgare, ambedue le lingue dichiarandosi l'vna con l'altra, Venetia : appresso Gio. Battista Marchio Sessa, \& fratelli. Un cotejo de esta obra con la de Villén de Biedma pronto revela que es aquella el modelo de esta, seguido muy de cerca. Cervantes fácilmente la habría podido consultar, ya que se volvió a imprimir en 1573, 1581, 1587, y 1599 y quedan todavía varios ejemplares en bibliotecas españolas.

3. Romero habla del «italiano aproximativo» de Cervantes. Vea su extensa nota $15,244-45$, en Cervantes 2004 . 


\section{Auristela}

La cuestión del corpus horaciano en el dieciséis español me parece de interés para el conocimiento de la génesis y la onomástica del Persiles por el siguiente trocito de las odas: tu pudica, tu proba/ perambulabis astra sidus aureum (Epodo 17, vv. 40-41). Llama la atención el calificar aquí a una mujer sidus aureum, 'estrella de oro', ya que, como reconoce la critica desde hace mucho, es este el significado del nombre Auristela y no se ha encontrado ningún empleo anterior. ${ }^{4}$ Como posible modelo se ha propuesto sólo uno , algo distinto en cuanto al significado sugerido: Aurismunda (¿limpia y dorada?). Aparece precisamente en otra novela bizantina, por otra parte casi seguramente conocida por Cervantes, Los amores de Clareo y Florisea y los trabajos de la sin ventura Isea de Nuñez de Reinoso (Cervantes, Persiles, 136, n. 9).

Si el novelista, confeccionando por esos años la trama, los nombres de los protagonistas y otros ingredientes, efectivamente hubiera visto su 'estrella de oro' en la obra horaciana, ¿habría pasado leyendo la traducción de Villén de Biedma? Parece que sí. Se habían hecho y editado en el siglo XVI traducciones castellanas de poemas sueltos, por supuesto, pero si nos basamos en el amplio y detallado estudio de Menéndez Pelayo, Horacio en España, no hay versión española de dicho epodo hecha antes. Por otra parte, la traducción castellana de los versos que nos interesan, además de su contenido idóneo para designar a la heroína de la novela (virtuosa hasta lo celestial) agrega al sentido del texto latín una frase que encaja de forma sorprendente en la trama: «tu buena yras como estrella de oro $\{a s t r a\}$ a las estrellas donde estaras colocada y tenida por Diosa». ${ }^{5}$ Las palabras «y tenida por Diosa» hacen pensar inmediatamente en la apariencia como diosa de Auristela en la Isla de los Pescadores; la frase no está presente en la versión italiana de Fabrini da Fighine.

Hay que tener en cuenta, sin embargo, que la idea de la apariencia divina de Auristela ante los pescadores, explícitamente descrita en esos términos, también podría - posiblemente - haber nacido en combinación con el deseo del autor de cumplir con una de las convenciones esenciales del género en el que se había propuesto competir con el más reconocido maestro. Como apuntan unánimemente los comentaristas de la novela bizantina, en ésta siempre hay un par de episodios en los que uno de los dos protagonistas (masculino y femenino) se presenta en clara asociación/identificación con un dios o una diosa. Era, también, una técnica utilizada en algunas obras, tanto narrativas como dramáticas, del diecisiete ${ }^{6}$. Pensando Cervantes en tal rasgo genérico,

4. Vea Baena, Julio, 1996 : El círculo y la flecha: principio y fin, triunfo y fracaso del Persiles. University of North Carolina Press, 144.

5. Vea Villén de Biedma, Juan (1599): Q. Horacio Flacco ... Sus obras con la declaración magistral en lengua castellana. Granada: Sebastián de Mena, f. 151 v.

6. Vea Lovëndi, Denes (1966): «Heliodors Aithiopika. Eine Literarische Würdigung», en Die Araber in der Alten Welt: Dritter Band, Anfänge der Dichtung- Der Sonnengott, Buchreligionen, Berlin: Walter de Gruyter, 1966, 146 y 152, como también Heliodoro (1979): Las etiópicas o Teágenes y Cariclea, introducción, traducción y notas de Emilio Crespo Güemes. Madrid: Gredos, 1979, 32- 
el topar con «tenida por Diosa» como calificativo de una mujer descrita como sumamente virtuosa y calificada de «Estrella de Oro» le podría haber sugerido lo apropiado del nombre para su mujer protagonista.

Por otra parte nuestro novelista, quien ha lanzado a sus personajes en un peregrinaje a Roma, podría primero haberle buscado un nombre que tuviera connotaciones religiosas, lógicamente vinculadas a la Virgen María. Ésta llevaba la tradicional advocación de «Stella maris»y, por consiguiente, si se le doblaba lo estelar tomando «Estrella de Oro» de Horacio, Cervantes tenía una forma de aludir a la máxima figura femenina católica. ${ }^{7} \mathrm{O}$ tal vez hallara antes el verso horaciano y después se le ocurriera el vínculo con la Vírgen. En todo caso la posibilidad de poner la imagen estelar en castellano le habría parecido demasiado llana, con sabor ni al mundo clásico ni a las novelas de caballerías.

La asociación de la virtud con el pasear por el mundo celestial se presenta de nuevo hacia el final del Persiles en relación con el catequismo que estudia Auristela, y en menor medida Periandro, en Roma: «Estas liciones ansí alegraron sus almas que las sacó de sí mismas y se las llevó a que paseasen los cielos, porque sólo en ellos pusieron sus pensamientos» (Cervantes, Persiles, 2004, IV, 5, 658). Tampoco debemos olvidar la caminata entre las estrellas como (irónico) premio a la virtud de Sancho Panza, jinete en Clavileño, que afirma haberse apeado para caminar y jugar con las Pléyadas.

\section{Cenotia}

Si suponemos, entonces, la intertextualidad de la «Estrella de Oro» horaciana en el nombre de la heroína, lo sorprendente del empleo de la imagen por el poeta clásico es que con tal epíteto se dirija Horacio a la repugnante bruja Canidia, frecuente blanco de sus denuncias poéticas. Sin embargo, tal contexto narrativo dentro del epodo bien puede arrojar luz no sólo sobre Auristela sino también sobre la ridícula y patética, pero de todas formas poderosa, figura de Cenotia, quien representa todo lo contrario de la princesa escandinava. Es morisca granadina, modelada en parte sobre la Camacha de Montilla, una hechicera de la época de Cervantes. Ha atraído la atención crítica por la etnia morisca que Cervantes le ha dado. Pero un estudio detenido del personaje y su empleo literario en la novela, como de la vida real de la hechicera, muestra que no se puede identificar cuáles eran las diferencias entre la hechicería morisca

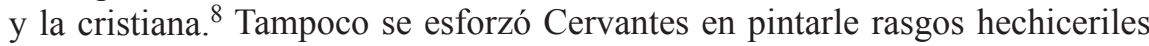

33. Sobre la identificación de los protagonistas con sendos dioses en obras españolas, vea Pelorson, Jean-Marc (2003): El desafio del Persiles seguido de un estudio onomástico por Dominique Reyre, Toulouse: Presses Universitaires du Mirail, 63.

7. Sobre la imagen de la protagonista como «estrella Polar», norte moral del protagonista, vea Pelorson, 2003, 19-20.

8. «Se trata de un campo de múltiples interferencias y la investigación debe establecer todavía si es posible tipificar por separado una hechicería morisca y una hechicería Cristiana». "La hechicera de Montilla es cristiana vieja, como ella misma confiesa en el proceso...» Vea Díez Fernández, José 
moriscos. ${ }^{9}$ Lo que tenemos, en cambio, es una hechicería no específicamente morisca, sino una más difundida y conocida. Cervantes hizo morisca a Cenotia, como judía a Julia, porque era un tópico que las mujeres de esos grupos, sentidos como enemigos, eran peligrosas y abusaban de poderes vinculados con los demonios. ${ }^{10}$ Por otra parte, los moriscos se habían convertido en un tema de actualidad que evocaba emoción dentro de los lectores por la largamente controvertida cuestión de su prevista expulsión.

Las hechiceras, como también la profecía hechiceril de la Isla Bárbara, sirven en el Persiles como obstáculos en la peregrinación de los protagonistas y como ejemplos, o tal vez símbolos, del mal que los tienta y amenaza (Díez y Aguirre, «Contexto histórico», 53-54). Su perfil es la que transmite una amplia y condenatoria tradición europea nacida de la romana. Más precisamente, parece ser la romana tal como la representa Horacio, el escritor romano que, con mucho, más versos enfoca en las hechiceras, ${ }^{11}$ como se ve leyendo el mismo epodo 17 ya citado en relación con Auristela.

Por otra parte, es innegable y se verá más abajo que El jardín de flores curiosas de Antonio de Torquemada, mediante Olao Magno y autores antiguos, recoge tres datos de la tradición clásica sobre los hechiceros que de él podría haber recogido Cervantes y utilizado en el Persiles: el papel de los magos del Medio Oriente como inventores de la magia, la descripción de los poderes mágicos sobre el mundo natural, y el deseo de los hechiceros de imponerle al mundo un imperio de mal. Sin embargo, el empleo cervantino de estos conceptos, si bien el ecléctico recogedor de historias los hubiera visto o revisto en Torquemada y de allí tomado algo, en los detalles corresponde mejor al texto horaciano.

El elogio estelar de Canidia se presenta en el poema horaciano como una patente mentira, irónicamente obvia, explícitamente ofrecida por el poeta como precio de que la hechicera anule un maleficio erótico que le ha hecho. El comentario de Villén de Biedma afirma que «Haze burla el Poeta de la sciencia de Canidia, y le ruega lo libre de vn mal que tiene» (Villén de Biedma, Horacio, f. 150r). La frase claramente encierra cierta contradicción, pero como veremos es la misma que encontramos en el Persiles. El narrador se burla del miedo de Cenotia ante las amenazas de Antonio padre, poniendo hincapié en que aquella no recurre a su jactada ciencia para salvarse (II, 8 , 335). Pero a la vez, la eficacia del hechizo no se cuestiona; tiene que aceptarse

Ignacio, y Luisa-Fernanda Aguirre (1992): «Contexto histórico y tratamiento literario de la 'hechicería' morisca y judía en el Persiles», Cervantes 12,48 y 52, n. 49.

9. «Aunque Cervantes ha recogido y desarrollado [en el Persiles] al menos tres casos de brujería y hechicería, no entra en los pormenores que se han conservado en los tratadistas o en los procesos inquisitoriales; no conocemos en qué lengua se hacen los hechizos, ni las palabras, ni los instrumentos... Más que retratos realistas o costumbristas parecen responder a funciones narrativas» (Díez y Aguirre 1992, 54).

10. Sobre el tratamiento literario en el Persiles de las etnias enemigas, vea Díez y Aguirre, 1992, 61.

11. Vea Tupet, Anne Marie (1976): La Magie dans la poésie latine. Paris: Les Belles Lettres, 284. 
para explicar que Antonio hijo repentinamente se alivie. Volveremos al final sobre los metas narrativos de ambos escritores aquí implícitos.

Dice, también, el comentario de Villén de Biedma, "Muy enojada Canidia, ansi de los agrauios passados, como de los en esta Oda contenidos, dize que no quiere perdonar al Poeta» (Villén de Biedma, Horacio, f. 152r). Sin embargo, como confirma la glosa del epodo hecha por Ogden, ${ }^{12}$ el lector nota que los versos burlonamente dejan entrever que Canidia está enamorada de Horacio, a pesar del mal que este le ha hecho divulgando sus bárbaros ritos. Que el hechizo impuesto en Horacio por Canidia sea del amor lo demuestra un verso que traduce Fabrini da Faghine hablando de lastimar «il cuore di lui, che nega di compiacere alla sua innamorata». ${ }^{13}$

Esta impresión la corrobora asimismo el último verso del poema, pronunciado por la voz de Canidia: «¿ plorem artis in te nil agentis exitus?», 'Debo llorar el fracaso de mi arte al no poder hacerte nada?' (Villén de Biedma, Horacio, v. 81). A primera vista se expresa en estos términos el desprecio de la poderosa hechicera por la insignificancia del poeta que la ha difamado, y tal es la interpretación que muestra Villén en su traducción. ${ }^{14}$ Pero Cervantes, maestro de la ironía del autor, habría visto que Horacio remata el poema, y con él sus obras centradas en Canidia, burlándose de la impotencia de quien acaba de jactarse de poderes inmensos, entre ellos un hechizo de atracción sexual a modo de venganza/seducción supuestamente infalible.

Algo parecido pasa con Cenotia y Antonio hijo. El hechizo de la bruja tendría que clasificarse entre los de odio, ${ }^{15}$ como el de la hechicera romana Julia pensado a quitarle la vida a Auristela. Claramente el narrador lo describe como forma de vengarse Cenotia del rechazo amoroso sufrido («con intención de vengarse del cruel y desamorado mozo», II, 8, 335), pero muy pronto hay señales de que Cenotia no ha dejado de desear a Antonio. Le asegura a Policarpo que el joven no morirá de su supuesta enfermedad, luego aconsejándole al rey que haga lo posible por retener a Antonio y Auristela en la isla. Resultan sus interesados consejos otra forma de hechizo.

Tal combinación de deseos de venganza con otros eróticos todavía encendidos sigue manifestándose de forma prominente en la narración: «Sacó

12. «The victim now of her erotic magic (always Canidia's chief concern in the major poems), Horace begs for pardon and concedes her abilities ....Horace's description of the state of his distress seems to express the experience of one suffering under a binding spell .... Horace does not explicitly say for whom he feels this desire, but Canidia is not shown elsewhere to work her erotic magic in anyone's interest but her own» (Ogden, 2002, 120).

13. Fabrini da Fighine, Horacio, f. 331v. La versión de Villén resulta claro, también: «al coraçon del que se niega a quien bien lo quiere» (Villén de Biedma, 1599, f. 151v).

14. Media página antes Villén agrega otro verso parecido en latín: «Lo cual siendo todo assi te pregunto \{ an priorem exitum artis nihil valentis\} si por ventura devo llorar el sucesso de mi arte, que tienes en poco, porque no vale nada» ['en tu deleznable opinión', podemos agregar] (Villén de Biedma, 1599,152v-153r). Después, al final, vuelve a la idea en un verso muy parecido que no traduce: «Plorem artis in te nihil habente exitum ?», el que parece significar, 'Debo llorar el fracaso de mi arte contra ti, que lo tienes en nada?' (153r).

15. Vea Cruz Casado, Antonio (2003): «Auristela Hechizada: Un caso de maleficia en el Persiles», en Sobre Cervantes. Alcalá de Henares: Centro de Estudios Cervantinos, 129. 
del quicio de una puerta los hechizos que había preparado para consumir la vida poco a poco del riguroso mozo, que con los de su donaire y gentileza la tenía rendida» ( II, 11, 353); «quiso por mano ajena vengar su agravio, sin privarse de la presencia de su desamorado bárbaro» (II, 11, 354); «ella, cruel y enamorada, daba trazas en su pensamiento cómo cumpliese el deseo del rey y el suyo» ( II, 11, 356); y "se volvieron a renovar en Cenotia sus mal nacidos deseos» (II, 13, 364).

Estos esfuerzos dirigidos a satisfacer fines eróticos también pueden tener relación con otro epodo, el quinto, donde Horacio habla del tormento impuesto por Canidia y tres colegas en un niño, a quien 'resecan' enterrándolo vivo delante de un plato de comida para que el deseo carnal, en forma de hambre y sed, llegue a calarle el cuerpo antes de que se muera. Canidia tiene pensado luego darle al hombre objeto de sus propios deseos la vejiga biliar y de las médulas del niño en un brebaje ${ }^{16}$ («exsecta uti medulla et aridum iecur/ amoris esset poculum», vv. 37-38) con el propósito de garantizar la atracción. La combinación de los órganos resecos (parecidos por su condición a unas cenizas) y un canibalismo de carne humana consumida en brebaje, todo para facilitar la unión sexual, hace difícil no pensar en la profecía de la Isla Bárbara. Canidia, efectivamente, también hace una profecía, y resulta esta muy parecida por su agresividad belicosa descarada: «vectabor umeris tunc ego inimicis eques,/ meaeque terra cedet insolentiae» ( Ep. 17, vv. 74-75). Con la imagen de un militar triunfante llevado en los hombros de sus enemigos, imponiendo así su insolente voluntad en toda la tierra, ofrece el mismo tipo de conquistador mundial inmoral. ${ }^{17}$

Los deseos eróticos, como se ve en estas imágenes, solían describirse en términos del fuego. Los autores del Malleus malificarum, 'Martillo contra las brujas', escribiendo hacia finales del siglo dieciséis y dentro de la tradición clásica heredada, declaran que toda la brujería nace de la ardiente lujuria. ${ }^{18}$ Se identificaba el lugar de la combustión precisamente en la médula de los

16. Al glosar este verso afirma Tupet: «doit être administrée rapidement sous une forme liquide, sans doute un breuvage» $(1976,314)$.

17. La profecía de la Isla Bárbara, por sus objetivos generales, podría tener algo que ver con la tradición recogida por Torquemada de que «de aquellas partes [septentrionales] ha de venir el Anticristo, que tan mortal enemigo ha de ser de todos». Vea Torquemada, Antonio de: Jardín de flores curiosas, edición, introducción y notas Giovanni Allegra. Madrid: Castalia, 1982, 445. En cuanto a la traducción de Villén de Biedma de los versos horacianos correspondientes, siguiendo la lectura italiana del texto latino cambia una de las palabras, sustituyendo «tuis» por «inimicis». Se pierde así unas de las connotaciones del triunfo marcial que resulta de una conquista de la tierra: «\{Vectabor tunc eques\} Sere lleuada luego a caballo [humeris tuis] sobre tus hombros: quiso dezir, que demas de lo dicho, le daria otra pena de que la tuuiesse sobre sus hombros, sin poderla desechar de si: \{terraque cedet meae insolentiae.\} y la tierra dara lugar a lo que yo quisiere» (Villén de Biedma, 1599, 152v). Sin embargo, la versión correcta del verso latino viene en la siguiente página en un cuadro céntrico como parte de un pasaje allí comentado, así que Cervantes se habría dado cuenta de la evidente sustitución de palabra.

18. Sobre el Malleus malificarum y las brujas del Coloquio de los perros vea Welles, Marcia (1990): «Cervantes' Coloquio de los Perros: Why the Witch?», Romance Languages Annual, 59194. La Celestina, por su parte, ofrece numerosas imágenes de la fuerza destructiva del amor carnal sentido como fuego. 
huesos, creencia subyacente en la imagen ya citada del niño torturado. De tales imágenes vendría también el tormento del poeta en el epodo 17, con las imágenes de fuego y cenizas que reflejan las ansias hechiceriles: "\{tu cales officina $\}$ tu ardes como calera y officina \{venenis Colchicis\} de los venenos de Colcos $\{$ donec cinis aridus\} hasta que convertido en ceniza \{ferar ventis iniuriosis\} sea lleuado de los vientos injuriosos» (Villén de Biedma, Horacio, f. $151 \mathrm{v}) .{ }^{19}$

Tal acoplamiento de lo erótico egoísta y desastroso con las hechiceras, y estas con el fuego, se observa en los primeros dos libros del Persiles. En el segundo, se recalca que Cenotia insiste en que se incendie la ciudad para darle la oportunidad de imponerle a Antonio sus atenciones sexuales (II, 13, 365), mientras que en el primero es mediante la profecía de un «antiguo hechicero» que se queman los corazones de los hombres forasteros. Tal fuego genera cenizas utilizadas en una prueba para demostrar quién es el más despiadado y salvaje. El ganador tendrá derecho a una toma de posesión sexual sin más afecto que el de la lujuria y el poder, condición que forma el rasgo principal de la brujería clásica. Después de un incendio de la isla similar al de la capital de Policarpo quedan sólo más cenizas y la desastrosa influencia de los vicios hechiceriles. $^{20}$

De esta forma el principal punto de contacto de Cenotia con la hechicería romana parece localizarse en el incendio del palacio motivado por la lujuria. Sin embargo, hay tres datos empíricos que juntos posibilitan tal enlace mediante los mismos nombres de Cenotia y Canidia. Primero, Covarrubias explica en cuanto a la palabra «cana», la que viene del latín «canus» (del mismo significado) y es el origen del nombre de Canidia, ${ }^{21}$ que «deste color buelve a los viejos por la falta del calor natural». O sea, había base en la cultura popular para que Cervantes sintiera un vínculo entre Canidia, la bruja de las canas, y el fuego vuelto cenizas.

Segundo, el nombre «Cenotia» lleva la ot del augmentativo despectivo que acecha en el nombre «Quijote». El narrador se burla de ella por presumir de joven y guapa: «una mujer... de hasta cuarenta años de edad (que, con el brío y donaire, debía de encubrir otros diez)... Sentáronse, y la dama (si en tantos años de edad es justo se le dé este nombre)...». Romero comenta el empleo de la palabra «dama»: «El uso español lo restringe a doncellas o mujeres que no hayan perdido la flor de su buen parecer, y señaladamente la emplea en

19. En el mismo poema a Canidia se le asocian las cenizas también por su costumbre, típica de su oficio, de revolver y reanimar las cenizas de los cadáveres de los pobres. Vea Tupet, 1976, 287.

20. «Cenotia es primero hechicera y luego consejera política... el narrador ... subraya la mala influencia que ejerce sobre el rey y el país». «Quizá no habría que descartar la connotación demoníaca del fuego en la 'solución' que pondrá en práctica Policarpo bajo la influencia de Cenotia» (Díez y Aguirre, 1992, 53, n. 54, 58, n. 64).

21. «D'après H. Duntzer, il semblerait issu de canus et non de canis, à l'aide du suffixe -idius/idia bien attesté par ailleurs. Il conviendrait donc à une femme aux cheveux blanchis» (Tupet, 1976, 296). Vea también Ogden, Daniel (2002): Magic, Witchcraft, and Ghosts in the Greek and Roman Worlds, Oxford University Press, 117 
las que quieren notar de hermosas» (II, 8, 329, n. 2). Cañizares, bruja de $E l$ coloquio de los perros, tiene entre 60 y 70 años, y el tener una edad avanzada representa un elemento básico del cuadro típico de las brujas desde los tiempos romanos. ${ }^{22}$ En pocas palabras, Cervantes recalca el envejecimiento de Cenotia, en contraste con sus deseos verdes vistos como poco decentes. Tercero, las dos hechiceras llevan nombres muy similares entre sí en cuanto a la forma. En conjunto, aunque desconozcamos los pasos concretos de la creación del nombre, las probabilidades son altas de que Canidia tuviera algo que ver.

\section{La hechicería romana}

Las hechiceras romanas se asociaban sobre todo con los destructivos deseos ilícitos. Se les atribuyen ansias del poder en general (Ogden, Magic, 124) y, como ya vimos, con frecuencia eróticas. Dentro del Persiles, como apuntan Díez y Aguirre, «en las tres historias [de hechiceras] la magia y el amor aparecen vinculados, y concretamente la magia y el amor deshonesto (e inmediato en las dos primeras, donde las hechiceras actúan por cuenta propia)» («Contexto histórico», 38, n. 11). En el Persiles se le ofrece Cenotia a Antonio hijo anunciando, «no te pido que seas mi esposo, sino que me recibas por tu esclava» (II, 8,333). El antiguo empleo de la magia para conseguir una relación sexual prohibida viene siendo en la tradición, al contrario de lo que finge Cenotia, una relación de esclavitud del hombre por medio de los hechizos de ligamento, como el que a Horacio le intenta imponer Canidia.

En cuanto al poder sobre el mundo natural, Cenotia evoca una tentadora visión de sus capacidades ante la imaginación del joven codiciado. Las brujas romanas también solían hablar de su habilidad de controlar el paisaje, el mar, y los cielos. Como señala Ogden, los escritores romanos suponen que mediante las hechiceras vuelven los ríos a su fuente, las montañas se anivelan, y caminan los bosques (como, por ejemplo, en Macbeth). Los vientos y nubes, la lluvia y la luz del sol, les obedecen. Hacen palidecer el sol y bajar la luna del cielo para lograr metas eróticos (Ogden, Magic, 124-25). Los poderes de los que se jacta Cenotia son en gran medida los mismos:

¿Ves este sol que nos alumbra? Pues si, para señal de lo que puedo, quieres que le quite los rayos y le asombre con nubes, pídemelo, que haré que a esta claridad suceda en un punto escura noche; o ya, si quisieres ver temblar la

22. Sobre la sexualidad frustrada de las viejas brujas de El coloquio de los perros, vea Cárdenas, Anthony J. (1993): «Rojas' Celestina as an Intertext for Cervantes' Witch Episode in the Coloquio de los Perros: from Sorceress to Witch», Crítica Hispana 15: 47-62. En la misma línea, si bien más sentido, es el comentario de Tupet: «Canidie n'est plus jeune: le detail est sans doute destiné à souligner son âge et ses infirmities, comme aussi une coquetterie de mauvais aloi, cherchant à lutter par tous les artifices contre les ravages du temps; mais il est surtout source de comique: la perte de fausses dents, effet que l'on pourrait croir d'invention modern, sans être du meilleur gout, engendre le rire à coup sûr» (Tupet, 1976, 290). 
tierra, pelear los vientos, alterarse el mar, encontrarse los montes, bramar las fieras o otras espantosas señales que nos representen la confusión del caos primero... (II, 8,330-31). ${ }^{23}$

Asimismo se afirma que Canidia sabe bajar las estrellas: «\{coelo derocare sydera reffixa, \} que pueden hazer baxar las estrellas fixas del cielo» (Villén de Biedma, 1599, f. 151r). Hay un marcado contraste, presente ya en Horacio, entre el acto de bajar las estrellas por motivos ilícitos y el subir a caminar entre ellas como premio a la virtud, este último conllevado por los nombres 'sidus aureum' (mentirosamente aplicado a Canidia) y 'Auristela', como se ha notado. El mismo vínculo entre la virtud y el pasear por el mundo celestial se presenta de nuevo hacia el final del Persiles en cuanto al catequismo que estudia Auristela, y en menor medida Periandro, en Roma.

Es a través de una ciencia oculta, por los conocimientos del mundo natural, y no simplemente por saber las hechiceras presionar a los demonios a la manera brujeril, que se hacen tales prodigios. Prosigue Cenotia:

tratamos con las estrellas, contemplamos el movimiento de los cielos, sabemos la virtud de las yerbas, de las plantas, de las piedras, de las palabras, $\mathrm{y}$, juntando lo activo a lo pasivo, parece que hacemos milagros ... (II, 8,331).

Canidia, de forma parecida, termina el epodo 17 cargando contra Horacio con una larga lista de sus poderes relativos al mundo natural, los que atribuye a su «arte» (v. 81).

Tal arte abarca, también, los conocimientos precisos para hacer enfermar y sanar a las personas. La lista de síntomas de los que se queja Horacio, provocados por Canidia, ofrece numerosos paralelos con los que afectan a Auristela cuando está hechizada por Julia. Resume Tupet las hazañas de Canidia como envenenadora: «elle l'a rendu malade par ses poisons, son teint a jauni, il est amaigri, ses cheveux ont blanchi, il a perdu le sommeil ...» (Tupet, Magic, 327). ${ }^{24}$ Cervantes nos cuenta:

23. Afirman Díez y Aguirre (1992, 52, n. 50) que este llamativo pasaje es de pura palabrería, pero sin colocarlo en ninguna tradición específica. Torquemada, siguiendo a Olao Magno, describe los poderes de una hechicera escandinava de forma similar: «Y según las cosas que hacía, era opinión entre las gentes que podía en un instante oscurecer el sol y la luna y estrellas, allanar las tierras, trastornar los montes, arrancar los árboles, secar los ríos, y hacer otras cosas semejantes» (Torquemada, 1982, 447-448). Anota Allegra: «Atribuye Olao Magno... a Hagberta ... rasgos típicos de la bruja literaria clásica, que puntualmente recalca Torquemada...» (Torquemada, 1982, 448, n. 182).

24. La lista completa viene traducida por Villén de Biedma así: «y la jubentud y fuerça que me hazia burlar de ti, como moço, ya se paso: agora es otro tiempo: ... y me ha dejado los huesos ... cubiertos con la piel ... descolorida, y el color macilento ... mis cabellos ya son canos ... con tus encantos , que por hazerme mal me has hecho viejo ... ningún descanso me aliuia del trabajo: ... la noche atormenta el dia ... y el dia atormenta la noche: quiso decir que de dia y de noche no reposaba ...ni puedo aliuiar el coraçon ... herido del espíritu de mis sospiros: y luego infiere una conclusión de mayor burla de la que a hecho ... de aquí se infiere que estoy convencido : ... para que yo miserable crea los encantos Sabellos ... atormentar el coraçon, del que se niega a quien bien lo quiere ... y ser atormentada la cabeça ... de los encantos viados de Marso ... que mas quieres que te diga, estas 
No había dos horas que estaba enferma y ya se le parecían cárdenas las encarnadas rosas de sus mejillas, verde el carmín de sus labios y topacios las perlas de sus dientes; hasta los cabellos le pareció que habían mudado color, estrechádose las manos y casi mudado el asiento y encaje natural de su rostro.... Auristela, en fin, iba enflaqueciendo por momentos y quitando las esperanzas de su salud a cuantos la conocían.... Auristela. La cual, ya flaca, ya descolorida, parecía que estaba llamando su vida a las aldabas de las puertas de la muerte (IV, 9-10, 684, 686, 688).

De la literatura romana se extrae un rasgo hechiceril más que genera eco en el Persiles. Le informa Cenotia a Antonio hijo que «mi estirpe es agarena; mis ejercicios, los de Zoroastes, y en ellos soy única» (II, 8, 330). ${ }^{25}$ En la literatura romana las hechiceras también se relacionaban con países y religiones exóticos, típicamente con Tesalia o Persia o el Medio Oriente en general, pero también con una tribu de la península italiana, los Marsos, asociada con las artes mágicas (Ogden, Magic, 124).

Finalmente, volvamos a la cuestión antes suscitada sobre el tratamiento literario de los poderes de Canidia y Cenotia. ¿Nos puede aclarar el poema horaciano porqué el narrador cervantino se burla del arte de Cenotia a la vez que la toma en serio para explicar enfermedades graves y curaciones casi milagrosas? Recuerdan Díez y Aguirre que «Menéndez Pelayo recoge otras obras en donde Cervantes se muestra escéptico o burlón sobre la brujería y la magia. Sólo encuentra en el Persiles un uso diferente que achaca a 'debilidad senil'...» («Contexto histórico», 34, n. 3) Tupet, quien más ha escrito en nuestros tiempos del detallado ataque de Horacio contra las hechiceras romanas, le atribuye dos motivos plausibles. Epicúreo y racionalista como el emperador Augusto, pretende respaldar la política de éste de combatir las supersticiones, «la enfermedad de su época», mediante tanto la risa como el horror. Por un lado quiere debilitar la creencia popular en los poderes de las hechiceras y a la vez revelar la depravada moral, la crueldad, de sus empresas. Por otro quiere que se le reconozca (y recompense más adelante) el peligro al que se ha expuesto tratando con tan formidables seres, aprovechándose así del terror que provocaban las artes negras hasta en los más sesudos pensadores ${ }^{26}$.

No queda claro en el último epodo hasta qué punto hemos de tomar como auténticos - o irónicos - los síntomas que Horacio afirma sufrir como

contenta? Luego para mas lisongearla y hazer mayor burla de ella finge que se arde todo, y da vozes diziendolo. O mare \& terras ... yo me abraso» (Villén de Biedma, 1599, f. 151v).

25. La vieja idea de Zoroastro como inventor de la magia se encuentra también en Torquemada: «[Los hechiceros] dejando de ser hombres, se vuelven demonios en sus obras, y no son pocos los que ha habido en el mundo muy famosos, entre los cuales los más nombrados fueron Zoroastes, Lucio Apuleyo y Apolonio Tianeo» (Torquemada, 1982, 325). Anota Allegra: «La tradición sobre Zoroastro, maestro e iniciador del arte mágica, es de antigua raigambre clásica. La recoge Plinio (Nat. Hist., XXX, 25-26), quien dice de la magia '... sine dubio illic orta in Perside a Zoroastre, ut inter auctores convenit'» (Torquemada 1982, 323, n. 124).

26. «En dénonçant les crimes des sorcières, en riant de leurs ridicules, Horace s'est peut-être liberé lui-même autant que ses contemporains». Vea toda la conclusión al largo capítulo que Tupet le dedica a Horacio, 1976, 328-329. 
resultado de los hechizos de Canidia. Cervantes, creyera o no en la magia, también cumple con la política dominante de su sociedad, la eclesiástica, y su negación de los poderes mágicos. Por tanto se burla de Cenotia. ${ }^{27} \mathrm{~A}$ la vez se aprovecha del voltaje emocional - o al menos de la «admiratio» tan utilizada en la novela - generado en sus lectores por tales historias más o menos espeluznantes, según la perspectiva del lector.

En conclusión, Cervantes encontró en dos epodos de Horacio recién publicados en castellano en la época de la formulación del Persiles no sólo la base de dos nombres. Encontró dos tipos extremados de mujer. La virtuosa Estrella de Oro, de una luminosidad religiosa, está breve pero sugerentemente evocada. La canosa hechicera despliega un ancho abanico de rasgos, actividades e imágenes plenamente paganos y mundanos. Por la inserción elogiosa de aquella en el meollo de la denuncia de esta, Horacio le ofreció al novelista un modelo para la juxta- y contra-posición, tan fecunda en nitidez y emoción, de la celestial Auristela y la demasiado humana Cenotia. También sugirió el claroscuro efectuado por la subida a las estrellas de una princesa en peregrinación al lado de un descenso a los fuegos y cenizas infernales de dos islas bárbaramente gobernadas.

\section{BIBLIOGRAFÍA}

Baena, Julio, El círculo y la flecha: principio y fin, triunfo y fracaso del Persiles, University of North Carolina Press, 1996.

Cárdenas, Anthony J., «Rojas' Celestina as an Intertext for Cervantes' Witch Episode in the Coloquio de los Perros: from Sorceress to Witch», Crítica Hispana, 15 (1993): 47-62.

Cervantes, Miguel de, Los trabajos de Persiles y Sigismunda, edición de Carlos Romero Muñoz, Madrid: Cátedra, 2004.

Cruz Casado, Antonio, «Auristela Hechizada: Un caso de maleficia en el Persiles», en Sobre Cervantes, Alcalá de Henares: Centro de Estudios Cervantinos, 2003, pp. 125-35.

Díez Fernández, José Ignacio, y Luisa-Fernanda AGUIRRE, «Contexto histórico y tratamiento literario de la 'hechicería' morisca y judía en el Persiles», Cervantes 12 (1992): 33-62.

Fabrini Da Fighine, L'opere d'Oratio poeta lirico / comentate da Giouanni Fabrini da Fighine in lingua uulgare toscana ; con ordine, che 'l uulgare e comento del latino: et il latino e comento del uulgare, ambedue le lingue dichiarandosi l'vna con l'altra, Venetia : appresso Gio. Battista Marchio Sessa \& fratelli, 1566.

Heliodoro, Las etiópicas o Teágenes y Cariclea, introducción, traducción y notas de Emilio Crespo Güemes, Madrid: Gredos, 1979.

Horacio, Horace, Odes and Epodes, edición y traducción de Niall Rudd, Harvard University Press, 2000.

Lovèndi, Denes, «Heliodors Aithiopika. Eine Literarische Würdigung», en Die Araber in der Alten Welt: Dritter Band, Anfänge der Dichtung- Der Sonnengott, Buchreligionen, Berlin: Walter de Gruyter, 1966, pp. 136-197.

27. En cuanto a la disminuyente creencia en los poderes hechiceriles a lo largo del siglo dieciséis vea Torquemada, 1982, 316-17, n. 118 
Menéndez Pelayo, Marcelino, Horacio en España, dos tomos, Madrid: Pérez Dubrull, 1877.

Ogden, Daniel, Magic, Witchcraft, and Ghosts in the Greek and Roman Worlds, Oxford University Press, 2002.

Pelorson, Jean-Marc, El desafio del Persiles, seguido de un estudio onomástico por Dominique Reyre, Toulouse: Presses Universitaires du Mirail, 2003.

Torquemada, Antonio de, Jardín de flores curiosas, edición, introducción y notas de Giovanni Allegra, Madrid: Castalia, 1982.

Tupet, Anne Marie, La Magie dans la poésie latine, Paris: Les Belles Lettres, 1976.

Villen de Biedma, Juan, Q. Horacio Flacco ... Sus obras con la declaración magistral en lengua castellana, Granada: Sebastián de Mena,1599.

Welles, Marcia, «Cervantes' Coloquio de los Perros: Why the Witch?», Romance Languages Annual, 1990: 591-94.

Recibido: 26 de abril de 2012

Aceptado: 30 de octubre de 2012

\begin{abstract}
Resumen
En la traducción de 1599 de un poema horaciano se lee, "tu buena yras como estrella de oro \{astra\} a las estrellas donde estaras colocada y tenida por Diosa". No sólo apunta al primer empleo literario conocido del nombre de Auristela, si bien en lengua castellana, sino también a la divina apariencia de ésta en la Isla de los Pescadores. Para mayor sorpresa, la mayor parte del mismo poema consiste en una denuncia de la destinataria del elogio, la repugnante hechicera Canidia. Esta, cual la Cenotia cervantina enamorada de Antonio hijo, desea a Horacio a la vez que lo atormenta por medio de hechizos. En ambos casos el narrador se burla de los pretendidos poderes de las hechiceras, pero sin cuestionar la eficacia de su magia en el caso narrado. Cenotia, típicamente enfocada por la crítica como morisca, muestra varios rasgos de la hechicería romana clásica. Entre ellos está su vínculo con el fuego y las cenizas, visto incluso en su nombre, el que emparenta con el de Canidia. Sus encendidos deseos, como los de los seguidores de un antiguo hechicero de la Isla Bárbara, terminan en fuegos devastadores. La juxtaposición de la celestial Auristela y la infernal Cenotia parece manar de la oda horaciana, y comparten ambos autores parecidos motivos al formular su tratamiento ambivalente de la hechicería.
\end{abstract}

Palabras clave: Auristela, Cenotia, hechicería, Horacio, cenizas, onomástica.

Title: Auristela and Cenotia, personalities from Horace in the Persiles.

\begin{abstract}
In the 1599 translation of a poem by Horace one finds: "You who are good, a golden star, will go among the stars \{astra\} where you will be placed and taken for a Goddess." This not only points to the first known literary use of the name of Auristela, albeit in Castilian translation, but also to her divine appearance on the Island of the Fishermen. A further surprise is that the greater part of this same poem consists of an accusation against the recipient of this praise, the disgusting sorceress Canidia. She, like Cervantes' Cenotia enamored of the younger Antonio, lusts after Horace at the same time that she tortures
\end{abstract}


him with hexes. In both cases the narrator mocks the powers claimed by the sorceresses, but without questioning the efficacy of their magic in the cases being narrated. Cenotia, usually focused on by critics in relation to her Morisco ethnicity, exhibits several traits of classic Roman sorcery. Among these is her link to fire and ashes, visible even in her name, which is related to that of Canidia. Her burning desire, like that of the followers of an ancient sorcerer on the Barbarous Isle, leads to devastating fires. The juxtaposition of the celestial Auristela with the infernal Cenotia seems to spring from Horace's poem, and both authors share similar motives in the formulation of their ambivalent treatment of sorcery.

Key words: Auristela, Cenotia, sorcery, Horace, ashes, onomastics. 